\title{
New Approaches to Donor Selection and Preparation in Heart Transplantation
}

\author{
Calvin K. W. Tong, MD \\ Kiran K. Khush, MD, MAS*
}

\author{
Address \\ "Cardiovascular Medicine, Stanford University, 300 Pasteur Drive, Falk CVRC 263, \\ Stanford, CA, 94305, USA \\ Email: kiran@stanford.edu \\ Published online: 23 March 2021 \\ (C) The Author(s), under exclusive licence to Springer Science+Business Media, LLC part of Springer Nature 2021
}

This article is part of the Topical Collection on Heart Failure

Keywords Heart transplantation - Marginal donor - Ex vivo perfusion - Donor selection - Donation after circulatory death

\begin{abstract}
Purpose of review With increasing survival of patients with stage $D$ heart failure, the demand for heart transplantation has increased. The supply of donor hearts remains relatively limited. Strategies have been investigated and new technologies have been developed to expand the current donor pool. These new approaches will be discussed herein.

Recent findings Donor hearts are often considered "marginal" due to risk factors such as older age, size mismatch with the intended recipient, prolonged ischemic time, presence of left ventricular hypertrophy, and hepatitis $B / C$ infection. We reviewed recent data regarding the use of donor hearts with these risk factors and suggest ways to safely liberalize current donor heart acceptance criteria. New technologies such as temperaturecontrolled transport systems and ex vivo cardiac perfusion methods have also demonstrated promising short-term and intermediate outcomes as compared with routine cold storage, by promoting heart preservation and enabling heart procurement from remote sites with shorter cold ischemic time. Recent use of hearts from donation after circulatory death donors has demonstrated comparable outcomes to conventional donation after brain death, which can further expand the current donor pool.

Summary Careful selection of "marginal" donor hearts, use of ex vivo cardiac perfusion, and acceptance of hearts after circulatory death may expand our current cardiac donor pool with comparable outcomes to conventional donor selection and preparation methods.
\end{abstract}




\section{Introduction}

With the advancement in heart failure therapies and mechanical circulatory support, more patients are now surviving with stage D heart failure. Heart transplantation is the final option for patients with heart failure refractory to medical or device-based therapies. The challenge facing the increasing demand for heart transplantation is the limited donor organ supply. Society guidelines [1] and consensus statement [2] have been published to aid with optimal donor selection in order to best utilize the scarce organ supply. Recently, there has been a growing interest in expanding the standard donor pool by accepting marginal donor hearts, incorporating novel transport systems to allow for remote procurement, and recommencement of donation after circulatory death. This article will explore recent approaches to expand the cardiac donor pool (Fig. 1).

\section{Donor selection}

Different characteristics of cardiac organ donors have been studied to understand their impact on post-transplant outcomes.

\section{Donor age}
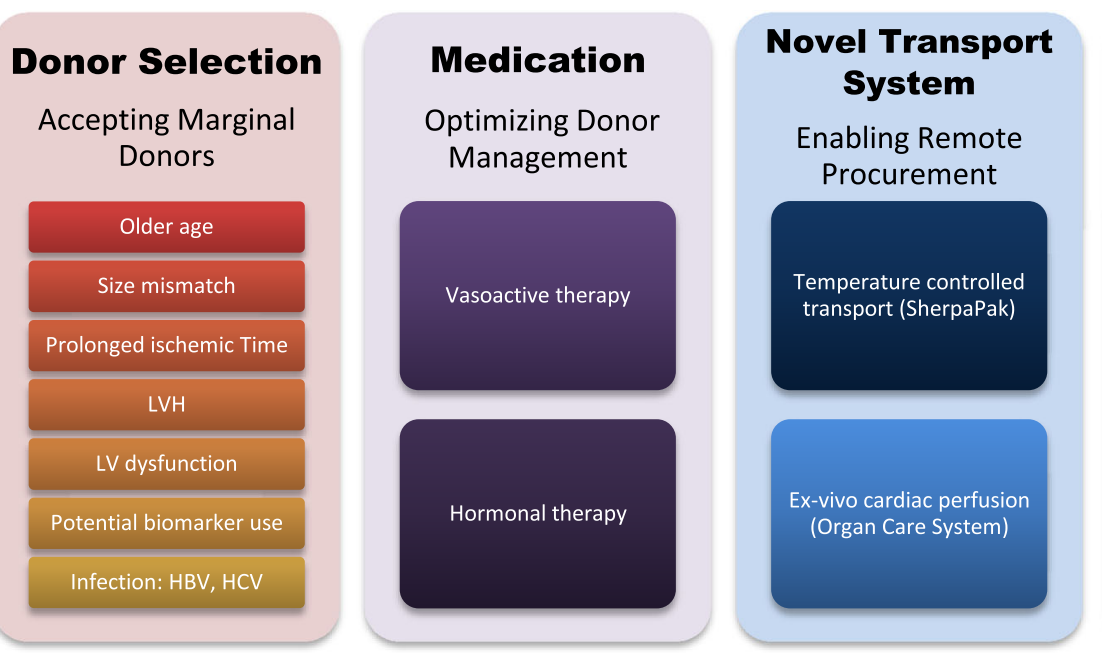

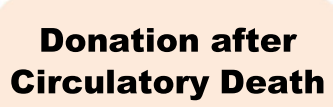

Expanding Donor Pool

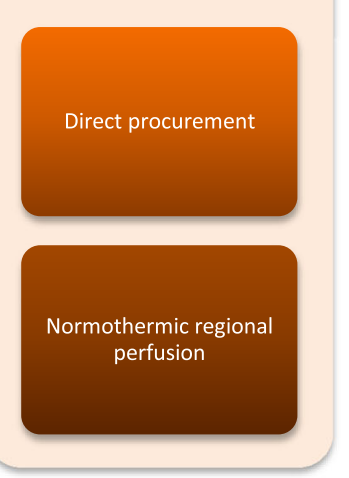

Fig. 1. Summary of new approaches to cardiac donor selection and preparation. LVH, left ventricular hypertrophy; HBV, hepatitis $B$; HCV, hepatitis C. 
that donor age $\geq 50$ years is associated with higher incidence of cardiac allograft vasculopathy (CAV) at 5 years (RR 1.67).

Therefore, donor age $\geq 50$ years portends a higher risk for CAV development and worse recipient survival. However, with the increased demand for donor hearts and a limited donor pool, treating clinicians must weigh the increased risk of accepting an older donor heart against the risk of remaining on the wait list and its associated morbidity and mortality.

\section{Donor/recipient size matching}

Undersized transplanted hearts could be disadvantaged compared to sizematched hearts. An undersized heart, for example, may require a higher heart rate to maintain adequate cardiac output due to smaller stroke volume [5]. In addition, for patients with mild to moderate pulmonary arterial hypertension, oversized donor hearts were often preferred, as it was believed that a larger heart may better tolerate higher pulmonary arterial pressures [6]. After reviewing the UNOS registry from 2007 to 2016, Kransdorf and colleagues [7•] that reported the donor/recipient predicted heart mass (PHM) ratio $\leq 0.86$ conferred increased 1-year mortality post-transplant (HR 1.34). They did not find differences in 1-year survival post-transplant for recipients with undersized donors based on height, weight, BMI, or BSA [7•].

Recently, the ISHLT 2019 Thoracic Transplant Registry report analyzed data on donor/recipient size matching by PHM and found that donor/recipient size mismatch was associated with increased recipient mortality $[8 \bullet \bullet]$. Both undersized (greater than $-10 \%$ PHM mismatch) and oversized (greater than $+10 \%$ PHM mismatch) donor hearts were associated with increased 1 year mortality $[8 \bullet \bullet]$. It is possible that the association between oversizing and increased mortality may be due to selection bias, with preferential use of oversized donor hearts for highrisk recipients such as those with pulmonary hypertension.

As donor hearts are procured from more remote locations, the cold ischemic time lengthens. Furthermore, after the US Organ Procurement and Transplantation Network revised the adult heart allocation system in 2018, the number of heart transplants increased [9], with a concurrent increase in median distance between donor and recipient centers from 83 to 216 miles [9]. With donor hearts procured from more remote locations, it was reported that the mean total ischemic increased from 3.0 to $3.4 \mathrm{~h}(P<.001)[9]$. A recent ISHLT registry report showed that ischemic time $<4 \mathrm{~h}$ is associated with improved recipient 30-day and 5-year survival compared to longer ischemic time. The survival curves between shorter and longer ischemic time diverge within the first few months, suggesting that ischemic time mostly impacts short-term post-transplant survival [10].

\section{Presence of donor left ventricular hypertrophy}

The use of donor hearts with left ventricular hypertrophy (LVH) has yielded mixed results in terms of recipient outcomes. Kuppahally and colleagues [11] reported that recipients of donor hearts with $\mathrm{LVH}(\geq 1.2 \mathrm{~cm})$ had worse survival and higher incidence of CAV. Subsequently, Pinzon and colleagues [12] reviewed the UNOS database between 2006 and 2010 with almost 3000 recipients and stratified donor 
hearts into groups without LVH $(<1.1 \mathrm{~cm})$, with mild LVH $(1.1$ to $1.3 \mathrm{~cm})$, and moderate-severe LVH $(\geq 1.4 \mathrm{~cm})$. They found similar 30-day and 1-year survival across recipients from all three groups. However, the hearts from donors with additional risk factors such as older age or prolonged cold ischemic time ( $\geq 4 \mathrm{~h}$ ) had worse survival [12], suggesting an interaction between LVH and other donor risk factors.

The 2010 ISHLT guidelines for the care of heart transplant recipients state that using hearts from donors with $\mathrm{LVH}$ with wall thickness $<1.4 \mathrm{~cm}$ and without accompanying ECG findings of LVH may be appropriate (Class IIa recommendation) [1].

\section{Donor left ventricular dysfunction}

Donor hearts with regional wall motion abnormalities or left ventricular dysfunction are often declined for transplant [13]. However, donor hearts with initial left ventricular dysfunction often demonstrate functional recovery during donor management [14]. This is thought to be due to the catecholamine surge after brain death which can cause transient LV dysfunction that is highly reversible [15]. Chen and colleagues [16] reviewed the UNOS database and studied clinical outcomes of recipients of donor hearts with three categories of left ventricular function, as measured by the ejection fraction (EF): $\mathrm{EF}<40 \%$, $\mathrm{EF} 40-50 \%$, and $\mathrm{EF} \geq 50 \%$. All recipient groups were found to have a similar incidence of postoperative stroke, primary graft failure, pacemaker requirement, acute rejection, and mortality at 1 year. Importantly, LV function normalized post-transplant in recipients of hearts with LV dysfunction. This study demonstrated that carefully selected donor hearts with left ventricular dysfunction can be used safely for transplantation.

\section{Donor biomarkers}

Biomarkers are not used routinely in donor selection. However, some biomarkers are nevertheless drawn during donor management, including troponin, natriuretic peptides, and several inflammatory markers. Prior studies have explored association of various levels of the above biomarkers with transplant outcomes.

\section{Troponin}

Troponin levels correlate to the degree of myocardial damage [17]. The catecholamine surge associated with brain death may cause transient myocardial ischemia and injury, resulting in elevated cardiac troponin levels [18]. Troponin levels in donors with subarachnoid hemorrhage were found to be elevated and were associated with left ventricular dysfunction; however, the left ventricular dysfunction was largely reversible and was not associated with post-transplant outcomes [19, 20]. A study of the UNOS database showed that receipt of a donor heart with an elevated troponin level in the context of preserved left ventricular function was not associated with primary graft failure, CAV, or mortality [21]. These findings suggest that cardiac troponin levels may not be a good indicator of donor heart suitability for transplantation in the setting of preserved ventricular function.

\section{Natriuretic peptides}

B-type natriuretic peptide (BNP) and N-terminal pro-B-type natriuretic peptide (NT-proBNP) are used for heart failure diagnosis and prognostication. These 
peptides are released in response to increased ventricular wall stress. An elevated NT-proBNP level has been found to be correlated with donor left ventricular dysfunction [22]. Higher donor BNP was also found to be correlated with lower cardiac output 12 days post-transplant and longer hospital stay [23]. Large studies are needed to further investigate the utility of donor natriuretic peptide levels for donor selection.

Donors with infection

The section examines infectious diseases of interest in cardiac donor selection in the modern era.

\section{Donors with hepatitis B}

Hepatitis B (HBV) infection is common worldwide; however, the prevalence varies geographically, with low rates in the United States and Western Europe and high rates in Southeast Asia and sub-Saharan Africa. HBV is unlikely to be transmitted with cardiac transplantation [24-26], as the majority of recipients have received vaccination or are treated with prophylactic lamivudine after transplantation. In one study, only 1 of 33 patients who did not receive prophylactic lamivudine or did not have prior immunity developed HBV viremia after receiving a heart from an HBV core antibody positive donor [25]. Notably, of the remaining 32 patients, 5 received lamivudine prophylaxis, 7 had prior HBV immunity, and the remainder had neither, and they all did not develop HBV. Therefore, the hearts from HBV-infected donors may be safely used for transplant, especially if recipients receive prior HBV vaccination or lamivudine prophylaxis.

\section{Donors with hepatitis C}

Hepatitis $\mathrm{C}(\mathrm{HCV})$ infection is another common blood-borne infection in the United States. A recent review of the Scientific Registry of Transplant Recipients (SRTR) database revealed that between 2000 to 2017, the 4th most common donor cause of death was from drug overdose $(10.8 \%)$ due to the on-going opioid epidemic. Overdose-death donors are more likely to be HCV positive (1.3\% vs $0.2 \%)$ [27].

$\mathrm{HCV}$ infection is likely to be transmitted from HCV viremic donors to recipients, with transmission rates from 80 to $100 \%$ [28, 29]. A review of the SRTR data from 1994 to 2003 found that recipients of HCV-positive donor hearts have higher short-term and long-term mortality, are more likely to develop CAV ( $8.8 \%$ vs 3.6\%), and are at increased risk of dying from liver disease (13.7\% vs $0.4 \%$ ) [30], compared to recipients of HCV-negative hearts. Similar findings were reported from a more recent SRTR analysis from 1995 to 2013 which showed that HCV-negative recipients of HCV-positive donor hearts have increased mortality (HR 1.78) and a higher incidence of graft failure causing death or re-transplantation [31].

Prior to 2014, the mainstay of HCV treatment was interferon-based, which was associated with cardiotoxicity and increased risk of acute rejection [32, 33]. Since 2014, several direct-acting antiviral drugs have been developed to treat HCV. These drugs are well tolerated and may achieve a sustained virologic response of up to $99 \%$ at 12 weeks [34]. Initial studies of sofosbuvir-based direct-acting antiviral drug 
regimens in liver and kidney transplant recipients with HCV demonstrated encouraging results with high sustained virologic response (87 to $100 \%)$ and minimal interaction with transplant immunosuppressive therapies [35, 36]. Given these promising findings, there has been rapidly growing interest in using hearts from $\mathrm{HCV}$-positive donors. Several reports have demonstrated similar survival, as well as similar incidence of acute rejection and malignancy, in recipients of HCV-positive donor hearts who were treated with direct-acting antivirals after transplant, compared to those who received HCV-negative donor organs [37, 38]. The largest study to date is a prospective observational cohort from Vanderbilt University that reported outcomes on 80 recipients of HCV-positive donor hearts from 2016 to 2019 [39••]. These recipients had excellent survival at 30 days (92\%) and at 1 year (90\%), comparable to recipients of HCV-negative donors [39••]. In addition, treatment with direct-acting antivirals resulted in $100 \%$ sustained virologic response at 12 weeks despite immunosuppression. However, the incidence of cardiac allograft vasculopathy at 1-year in recipients of HCV-positive donor hearts was increased

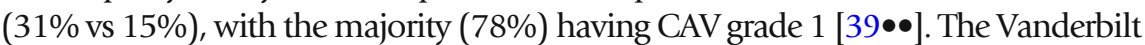
group also reported a trend towards higher incidence of severe primary graft dysfunction in recipients of HCV+ donor hearts. They attributed this observation to the fact that HCV-positive hearts were preferentially offered to candidates with critical illness who were receiving mechanical circulatory support, which is also a risk

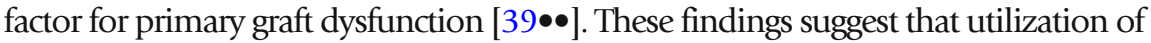
hearts from HCV-positive donors is safe and feasible and represents an important way to expand the donor pool in the modern era. Further studies are needed to better understand long-term outcomes after transplantation of HCV-positive donor hearts.

\section{Donors with HIV}

Currently, cardiac transplantation from donors with HIV is restricted to research protocols. A case of unintentional HIV transmission due to laboratory error was reported [40]. The recipient received antiretroviral therapy within $48 \mathrm{~h}$ posttransplant and was alive and well at 4 years. A study involving 27 kidney transplants from HIV-positive donors to HIV-positive recipients demonstrated short-term safety [41]. Due to a multitude of ethical implications, research in this area will likely be limited.

\section{Donor selection during the COVID-19 pandemic}

Given the uncertainty of donor COVID-19 infection on transplant outcomes, patients with COVID-19 infection are excluded from organ donation. It has been recommended that COVID-19 risk assessment be implemented by obtaining targeted donor travel and social history and COVID-19 testing during donor management [42]. Depending on the trajectory of the pandemic and immunization status, donor selection criteria regarding COVID-19 infection may evolve.

\section{Donor management}

Brain death causes a systemic inflammatory response and neurohormonal imbalance, which can result in hemodynamic instability and donor organ 
dysfunction. Use of vasoactive therapy and hormonal replacement therapy are discussed below.

Vasoactive therapy

There are no definitive guidelines for the use of vasoactive therapy in brain dead donors [43]. However, several studies have investigated the effects of different vasoactive therapies on donor heart function.

Norepinephrine and epinephrine are often used in the critical care unit for hemodynamic support. However, norepinephrine and epinephrine may cause downregulation of beta-adrenergic receptors, and this could theoretically worsen donor heart contractility post-transplant [44]. Studies performed to date have reported divergent results on the impact of norepinephrine and epinephrine on donor heart function. Norepinephrine has been reported to be associated with lower donor right ventricular contractility and poorer recipient survival [45-47]. On the contrary, a retrospective analysis of German registry data demonstrated no difference in recipient survival by donor norepinephrine administration [48]. Currently, use of vasoactive therapy during donor management varies substantially between donor hospitals and organ procurement organizations.

Brain death results in deficits in production of endogenous hormones, such as cortisol, vasopressin, and thyroid hormone. A retrospective cohort study reported that combination hormonal replacement during donor management with corticosteroids, vasopressin, and thyroid hormone, as compared to no or partial hormonal replacement, was associated with better recipient 1 year survival $(89.9 \%$ vs $83.9 \%)$ and reduced incidence of early cardiac allograft dysfunction (OR 0.52) [49].

Vasopressin level falls after brain death, which can lead to hemodynamic compromise and a catecholamine surge [50]. Administration of vasopressin during donor management is postulated to reduce catecholamine requirement and has been associated with improved donor cardiac function [51]. Furthermore, one study observed improved cardiac index (from 3.18 to $3.72 \mathrm{~L} \mathrm{~min}^{-1} \mathrm{~m}^{-2)}$ after substitution of norepinephrine with vasopressin [51]; definitive studies, however, are lacking.

There is conflicting evidence supporting isolated thyroid hormone replacement. While case series have reported a beneficial effect of thyroid hormone therapy during donor management, placebo controlled trials have not demonstrated any benefit of isolated thyroid hormone therapy on donor cardiac index and vasoactive therapy requirements [52].

\section{Temperature-controlled donor heart transport}

Donor organ transport is one of the final steps in donor management. During donor organ transport, ischemic injury ensues. Cold storage systems are used to slow down the ischemic injury process [53]. Traditional cold storage systems could result in uneven cooling and freeze injury to the donor heart. The novel SherpaPak cardiac transport system (Paragonix) is the only US Food and Drug 
Administration-approved system that maintains uniform cooling of the donor heart [54]. Procurement with the SherpaPak involves filling the organ canister with cold preservation solution. The donor heart is perfused with standard solution followed by procurement. The procured heart is then anchored in the organ canister and the organ canister is placed within the outer canister, which is surrounded by ice packs. The system contains a temperature sensor and the ice packs maintain a steady temperature of 4 to $8{ }^{\circ} \mathrm{C}$. Naito and colleagues [54] reported their experience using the SherpaPak to transfer donor hearts with a transportation time within the SherpaPak of $3 \mathrm{~h} 25 \mathrm{~min}$ and a total ischemic time of $5 \mathrm{~h}$ and $12 \mathrm{~min}$ without organ dysfunction. They suggest that the SherpaPak system could reduce the risk of primary graft failure by optimizing temperature during transport [54]. Further studies are needed to determine whether the SherpaPak could expand the donor pool by allowing for longer ischemic time.

As suggested earlier, prolonged ischemic time, especially $>4 \mathrm{~h}$, is associated with early graft dysfunction and reduced recipient survival. Rather than relying on static cold storage, which is the current standard of care during transport, organ preservation techniques have been developed that allow for ex vivo cardiac perfusion in order to preserve donor organ function and expand the donor pool by enabling procurement from distant locations $[55,56]$. Different methods of ex vivo cardiac perfusion have been described, including normothermic and hypothermic ex vivo perfusion.

The Organ Care System (OCS; Transmedics) is the only normothermic ex vivo perfusion platform available clinically. It is a portable system allowing temperature-regulated and oxygenated blood to perfuse the donor heart, which continues beating and remains metabolically active during transport. In 2015, the ex vivo perfusion of donor hearts for human heart transplantation (PROCEED II) trial evaluated clinical outcomes when using the OCS compared to static cold storage for donor heart transport. PROCEED II was a prospective, open-label, multicenter randomized trial that enrolled 130 donors, with 67 randomly assigned to the OCS arm and the remaining assigned to static cold storage. Thirty-day recipient and graft survival, adverse events, and severe rejection rates were found to be similar between the OCS and cold storage groups [57]. The mean cold ischemic time for the OCS group was $113 \mathrm{~min}$, compared to $195 \mathrm{~min}$ in the control group [57]. A follow-up study of a subset of the PROCEED II cohort demonstrated no difference in 2-year survival, CAV devel-

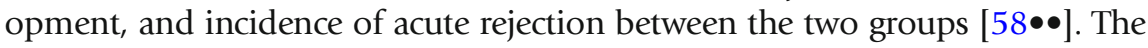
OCS was also studied in the single-arm OCS Heart EXPAND Trial, which included marginal donors with an anticipated total ischemic time of $\geq 4 \mathrm{~h}$ or $\geq 2 \mathrm{~h}$ with LVH, EF $40-50 \%$, downtime $\geq 20 \mathrm{~min}$, and/or age $>55$ years. With a mean perfusion time of $6.35 \mathrm{~h}$, recipient short-term survival (95\% 30-day and $88 \%$ at 6 months) and incidence of graft dysfunction at $24 \mathrm{~h}$ after transplant (10.7\%) for the 75 donor hearts perfused with the OCS were acceptable [59].

Hypothermic ex vivo perfusion infuses cold preservation solution into the donor coronary arteries to deliver oxygen and remove metabolites. Nilsson recently reported the first in-human experience of their nonischemic heart preservation (NIHP) system in which the donor heart 
is perfused with a cold $\left(8{ }^{\circ} \mathrm{C}\right)$ mixture of oxygenated cardioplegic solution and red blood cells. They studied the NIHP system in a nonrandomized phase II study and applied this system to 6 donor hearts [60]. The median preservation time in the NIHP group was $223 \mathrm{~min}$ as compared to $194 \mathrm{~min}$ in the static cold storage group. Recipients of the hearts transported with NIHP had 100\% event-free survival (including PGD within $24 \mathrm{~h}$, ECMO use within 7 days, or acute cellular rejection greater than $2 \mathrm{R}$ within 180 days) at 6 months as compared to $72 \%$ of patients within the static cold storage group. This finding was attributed to less endothelial damage and less ischemia/reperfusion injury associated with NIHP system. It was also proposed that, in the event of interruption to the ex vivo perfusion system, the hypothermic NIHP system provides additional protection to the donor heart as compared to a normothermic system [60].

These technologies support development of ex vivo cardiac perfusion systems as a viable way to expand donor heart utilization by allowing procurement from remote locations, reducing ischemia/reperfusion injury, and enabling further assessment of "marginal" donor hearts.

\section{The new era: recommencement of donation after circulatory death}

Donation after circulatory death (DCD) donors have irreversible brain injury but do not meet standard brain death criteria. The first DCD heart transplant was performed by Dr. Christiaan Barnard in 1967 [61]. However, over the decade following Barnard's DCD transplant, brain death became legally accepted and, as the function of the hearts from donation after brain death (DBD) donors could be readily assessed before procurement, this led to a lack of enthusiasm for DCD transplantation. Over the past decade, due to the increasing demand for donor hearts and efforts to expand the donor pool, DCD transplantation has been recommenced in Europe, Australia, and the USA.

DCD donor selection criteria differ between centers and regions. The Royal Papworth Hospital group in the UK selects donor aged 18 to 57 years and ejection fraction $>50 \%$ prior to withdrawal of life support therapy, who have no history of myocardial infarction, coronary or valvular heart disease, congenital heart disease, insulin-dependent diabetes, hepatitis B and C/HIV infection, or history of malignancy [62••]. The donor selection criteria for the St. Vincent's Hospital group in Australia are slightly different than the Royal Papworth group. Their initial donor selection criteria from July 2014 to December 2017 included donor age $<40$ years with no prior history of cardiac disease, stable hemodynamics with minimal inotropic/vasopressor support, and $\leq 30 \mathrm{~min}$ warm ischemic time from withdrawal from life support. In January 2018, the St Vincent's group expanded their DCD donor acceptance criteria to include donors age $<55$ years and refined their acceptable warm ischemic time to $30 \mathrm{~min}$ from systolic $\mathrm{BP}<90 \mathrm{mmHg}[63 \bullet \bullet]$. 


\section{DCD donor heart procurement}

Several techniques have been developed to alleviate the myocardial dysfunction caused by ischemia/reperfusion injury, including avoidance of hypothermia and supplementation of the perfusion solution [64, 65]. Normothermic ex vivo perfusion with the OCS has allowed for better organ preservation and has enabled viability assessment of DCD hearts [66]. The majority of centers utilize direct procurement followed by ex vivo perfusion (DP-ESP), with donor in situ cardioplegia followed by rapid explantation and reanimation in ex situ normothermic perfusion on the OCS. In addition to the DP-ESP method, the Royal Papworth Hospital also uses normothermic regional perfusion followed by ex vivo perfusion (NRP-ESP) - wherein perfusion is initially restored within the donor in situ using extracorporeal membrane oxygenation (ECMO) with arch vessel cross-clamping to avoid cerebral perfusion, and assessment of donor cardiac function prior to transport in the OCS. With DP-ESP, the heart is inspected visually for evaluation, whereas NRP-ESP allows for additional cardiac assessment including echocardiography. These techniques for DCD heart procurement have been reported to have similar 30-day survival outcomes as compared to the hearts procured from brain dead donors [67].

\section{DCD recipient outcomes}

Messer and colleagues published the Papworth Hospital DCD experience of 26 DCD heart transplants. They reported similar 90-day survival between the DCD and DBD groups ( $92 \%$ vs $96 \%$, respectively, $p=1.00$ ). There was no difference in outcomes between DP-ESP and NRP-ESP for DCD heart retrieval. The cause of death for the 3 DCD recipients who died within 90 days included primary graft dysfunction, opportunistic fungal infection, and antibody mediated rejection $[62 \bullet \bullet]$.

More recently, the St Vincent's Hospital group reported their 5-year DCD experience. They performed 69 DCD heart retrievals, of which 32 were transplanted (the remainder did not progress to circulatory arrest within 30 mins from withdrawal from life support, were declined for transplant due to inadequate recovery of left ventricular function, or had OCS failure). Ten DCD recipients required ECMO due to delayed graft function. The survival rates comparing DCD and DBD recipients were similar at 1,3, and 5 years, 96\%, $94 \%$, and $94 \%$ for DCD recipients compared to $89 \%, 83 \%$, and $82 \%$ for DBD recipients, respectively [68].

\section{Conclusion}

Due to the increasing demand for donor hearts, the criteria for acceptable organs are being challenged. Donors that were once viewed as marginal are being increasingly accepted for transplantation. Reassuringly, studies have demonstrated excellent survival outcomes after transplantation of donor hearts with left ventricular dysfunction. As well, with the advent of modern therapeutics and technologies, donor with HCV infection can now be safely used for transplantation, with administration of direct-acting antiviral therapy to the recipient. Donor hearts can be procured remotely and transported via temperature-controlled systems or ex vivo cardiac perfusion, and donation after circulatory death donors can now be included in the cardiac donor pool. 
Evidence-based donor selection and management guidelines may consolidate our current knowledge, in order to maximize the use of available donor hearts for transplantation.

\section{Compliance with Ethical Standards}

\section{Conflict of Interest}

Calvin K. W. Tong has no potential conflicts of interest. Kiran K. Khush is the principal investigator of NIH grant R01HL125303 "Evidence Based Evaluation and Acceptance of Donor Hearts for Transplantation."

\section{Human and Animal Rights and Informed Consent}

This article does not contain any studies with human or animal subjects performed by any of the authors.

\section{References and Recommended Reading}

Papers of particular interest, published recently, have been

highlighted as:

- Of importance

$\bullet \quad$ Of major importance

1. Costanzo MR, Dipchand A, Starling R, Anderson A, Chan M, Desai S, et al. The International Society of Heart and Lung Transplantation Guidelines for the care of heart transplant recipients. J Heart Lung Transplant. 2010;29(8):914-56. https://doi.org/10.1016/j.healun. 2010.05 .034 .

2. Kobashigawa J, Khush K, Colvin M, Acker M, Van Bakel A, Eisen H, et al. Report from the American Society of Transplantation conference on donor heart selection in adult cardiac transplantation in the United States. Am J Transplant. 2017;17(10):2559-66. https://doi.org/10. 1111/ajt.14354.

3.• Khush KK, Potena L, Cherikh WS, Chambers DC, Harhay MO, Hayes D Jr, et al. The International Thoracic Organ Transplant Registry of the International Society for Heart and Lung Transplantation: 37th adult heart transplantation report-2020; focus on deceased donor characteristics. J Heart Lung Transplant. 2020;39(10):1003-15. https://doi.org/10.1016/j. healun.2020.07.010

This ISHLT registry report identifies donor characteristics between 1992 to 2018 that influence post transplant outcome.

4. Roig E, Almenar L, Crespo-Leiro M, Segovia J, Mirabet S, Delgado J, et al. Heart transplantation using allografts from older donors: multicenter study results. J Heart Lung Transplant. 2015;34(6):790-6. https://doi. org/10.1016/j.healun.2014.10.006.

5. Mather PJ, Jeevanandam V, Eisen HJ, Pina IL, Margulies $\mathrm{KB}$, McClurken J, et al. Functional and morphologic adaptation of undersized donor hearts after heart transplantation. J Am Coll Cardiol. 1995;26(3):73742. https://doi.org/10.1016/0735-1097(95)00216-Q.
6. Goland S, Czer LS, Kass RM, De Robertis MA, Mirocha J, Coleman B, et al. Pre-existing pulmonary hypertension in patients with end-stage heart failure: impact on clinical outcome and hemodynamic follow-up after orthotopic heart transplantation. J Heart Lung Transplant. 2007;26(4):312-8. https://doi.org/10.1016/j. healun.2006.12.012.

7. $\quad$ Kransdorf EP, Kittleson MM, Benck LR, Patel JK, Chung JS, Esmailian F, et al. Predicted heart mass is the optimal metric for size match in heart transplantation. J Heart Lung Transplant. 2019;38(2):156-65. https:// doi.org/10.1016/j.healun.2018.09.017

This retrospective analysis of the UNOS registry between 2007 and 2016 identifies the optimal size match metric to predict survivial outcome post heart transplant and determined that PHM is the optimal metric for size match in heart transplantation.

8.• Khush KK, Cherikh WS, Chambers DC, Harhay MO, Hayes D Jr, Hsich E, et al. The International Thoracic Organ Transplant Registry of the International Society for Heart and Lung Transplantation: Thirty-sixth adult heart transplantation report - 2019; focus theme: Donor and recipient size match. J Heart Lung Transplant. 2019;38(10):1056-66. https://doi.org/10.1016/j. healun.2019.08.004

This ISHLT registry report presents details on donor-recipient size match and identifies PHM match within 10\% portends the best 1-year and 5-year survivial post hreat transplant.

9. Goff RR, Uccellini K, Lindblad K, Hall S, Davies R, Farr $\mathrm{M}$, et al. A change of heart: preliminary results of the US 2018 adult heart allocation revision. Am J Transplant. 
2020;20(10):2781-90. https://doi.org/10.1111/ajt. 16010.

10. Lund LH, Khush KK, Cherikh WS, Goldfarb S, Kucheryavaya AY, Levvey BJ, et al. The Registry of the International Society for Heart and Lung Transplantation: Thirty-fourth Adult Heart Transplantation Report2017; Focus Theme: Allograft ischemic time. J Heart Lung Transplant. 2017;36(10):1037-46. https://doi. org/10.1016/j.healun.2017.07.019.

11. Kuppahally SS, Valantine HA, Weisshaar D, Parekh H, Hung YY, Haddad F, et al. Outcome in cardiac recipients of donor hearts with increased left ventricular wall thickness. Am J Transplant. 2007;7(10):2388-95. https://doi.org/10.1111/j.1600-6143.2007.01930.x.

12. Pinzon OW, Stoddard G, Drakos SG, Gilbert EM, Nativi JN, Budge D, et al. Impact of donor left ventricular hypertrophy on survival after heart transplant. Am J Transplant. 2011;11(12):2755-61. https://doi.org/ 10.1111/j.1600-6143.2011.03744.x.

13. Khush KK, Menza R, Nguyen J, Zaroff JG, Goldstein BA. Donor predictors of allograft use and recipient outcomes after heart transplantation. Circ Heart Fail. 2013;6(2):300-9. https://doi.org/10.1161/ CIRCHEARTFAILURE.112.000165.

14. Zaroff JG, Babcock WD, Shiboski SC. The impact of left ventricular dysfunction on cardiac donor transplant rates. J Heart Lung Transplant. 2003;22(3):334-7. https://doi.org/10.1016/s1053-2498(02)00554-5.

15. Mohamedali B, Bhat G, Zelinger A. Frequency and pattern of left ventricular dysfunction in potential heart donors: implications regarding use of dysfunctional hearts for successful transplantation. J Am Coll Cardiol. 2012;60(3):235-6. https://doi.org/10.1016/j.jacc. 2012.04.016.

16. Chen CW, Sprys MH, Gaffey AC, Chung JJ, Margulies $\mathrm{KB}$, Acker MA, et al. Low ejection fraction in donor hearts is not directly associated with increased recipient mortality. J Heart Lung Transplant. 2017;36(6):611-5. https://doi.org/10.1016/j.healun.2017.02.001.

17. Sharma S, Jackson PG, Makan J. Cardiac troponins. J Clin Pathol. 2004;57(10):1025-6. https://doi.org/10. $1136 /$ jcp. 2003.015420.

18. Dronavalli VB, Banner NR, Bonser RS. Assessment of the potential heart donor: a role for biomarkers? J Am Coll Cardiol. 2010;56(5):352-61. https://doi.org/10. 1016/j.jacc.2010.02.055.

19. Deibert E, Barzilai B, Braverman AC, Edwards DF, Aiyagari V, Dacey R, et al. Clinical significance of elevated troponin I levels in patients with nontraumatic subarachnoid hemorrhage. J Neurosurg. 2003;98(4):741-6. https://doi.org/10.3171/jns.2003. 98.4.0741.

20. Deibert E, Aiyagari V, Diringer MN. Reversible left ventricular dysfunction associated with raised troponin I after subarachnoid haemorrhage does not preclude successful heart transplantation. Heart. 2000;84(2):205-7. https://doi.org/10.1136/heart.84. 2.205 .
21. Madan S, Saeed O, Shin J, Sims D, Goldstein D, Pina I et al. Donor troponin and survival after cardiac transplantation: an analysis of the United Network of Organ Sharing Registry. Circ Heart Fail. 2016;9(6). https:// doi.org/10.1161/CIRCHEARTFAILURE.115.002909.

22. Dronavalli VB, Ranasinghe AM, Venkateswaran RJ, James SR, McCabe CJ, Wilson IC, et al. N-terminal probrain-type natriuretic peptide: a biochemical surrogate of cardiac function in the potential heart donor. Eur J Cardiothorac Surg. 2010;38(2):181-6. https://doi.org/ 10.1016/j.ejcts.2010.01.024.

23. Vorlat A, Conraads VM, Jorens PG, Aerts S, Van Gorp S, Vermeulen T, et al. Donor B-type natriuretic peptide predicts early cardiac performance after heart transplantation. J Heart Lung Transplant. 2012;31(6):57984. https://doi.org/10.1016/j.healun.2012.02.009.

24. De Feo TM, Poli F, Mozzi F, Moretti MP, Scalamogna M, Collaborative Kidney L, et al. Risk of transmission of hepatitis B virus from anti-HBC positive cadaveric organ donors: a collaborative study. Transplant Proc. 2005;37(2):1238-9. https://doi.org/10.1016/j. transproceed.2004.12.041.

25. Pinney SP, Cheema FH, Hammond K, Chen JM, Edwards NM, Mancini D. Acceptable recipient outcomes with the use of hearts from donors with hepatitis-B core antibodies. J Heart Lung Transplant. 2005;24(1):34-7. https://doi.org/10.1016/j.healun. 2003.09.036.

26. Ko WJ, Chou NK, Hsu RB, Chen YS, Wang SS, Chu SH, et al. Hepatitis B virus infection in heart transplant recipients in a hepatitis B endemic area. J Heart Lung Transplant. 2001;20(8):865-75. https://doi.org/10. 1016/s1053-2498(01)00280-7.

27. Phillips KG, Ranganath NK, Malas J, Lonze BE, Gidea CG, Smith DE, et al. Impact of the opioid epidemic on heart transplantation: donor characteristics and organ discard. Ann Thorac Surg. 2019;108(4):1133-9. https://doi.org/10.1016/j.athoracsur.2019.03.076.

28. Pfau PR, Rho R, DeNofrio D, Loh E, Blumberg EA, Acker MA, et al. Hepatitis $\mathrm{C}$ transmission and infection by orthotopic heart transplantation. J Heart Lung Transplant. 2000;19(4):350-4. https://doi.org/10. 1016/s1053-2498(00)00062-0.

29. File E, Mehra M, Nair S, Dumas-Hicks D, Perrillo R. Allograft transmission of hepatitis $C$ virus infection from infected donors in cardiac transplantation. Transplantation. 2003;76(7):1096-100. https://doi. org/10.1097/01.TP.0000088663.76640.C9.

30. Gasink LB, Blumberg EA, Localio AR, Desai SS, Israni $\mathrm{AK}$, Lautenbach E. Hepatitis $\mathrm{C}$ virus seropositivity in organ donors and survival in heart transplant recipients. JAMA. 2006;296(15):1843-50. https://doi.org/ 10.1001/jama.296.15.1843.

31. Stepanova M, Locklear T, Rafiq N, Mishra A, Venkatesan C, Younossi ZM. Long-term outcomes of heart transplant recipients with hepatitis $C$ positivity: the data from the U.S. transplant registry. Clin Transpl. 2016;30(12):1570-7. https://doi.org/10.1111/ctr. 12859. 
32. Aljumah AA, Saeed MA, Al Flaiw AI, Al Traif IH, Al Alwan AM, Al Qurashi SH, et al. Efficacy and safety of treatment of hepatitis $\mathrm{C}$ virus infection in renal transplant recipients. World J Gastroenterol. 2012;18(1):55-63. https://doi.org/10.3748/wig.v18. i1.55.

33. Wang BY, Chang HH, Chen IM, Shih CC, Yang AH. Peginterferon alpha-2b and acute allograft failure in a heart transplant recipient. Ann Thorac Surg. 2010;89(5):1645-7. https://doi.org/10.1016/j. athoracsur.2009.09.084

34. Afdhal N, Zeuzem S, Kwo P, Chojkier M, Gitlin N, Puoti $\mathrm{M}$, et al. Ledipasvir and sofosbuvir for untreated HCV genotype 1 infection. N Engl J Med. 2014;370(20):1889-98. https://doi.org/10.1056/ NEJMoa1402454.

35. Fontana RJ, Brown RS Jr, Moreno-Zamora A, Prieto M, Joshi S, Londono MC, et al. Daclatasvir combined with sofosbuvir or simeprevir in liver transplant recipients with severe recurrent hepatitis $\mathrm{C}$ infection. Liver Transpl. 2016;22(4):446-58. https://doi.org/10.1002/ lt. 24416

36. Elfeki MA, Abou Mrad R, Modaresi Esfeh J, Zein NN, Eghtesad B, Zervos X, et al. Sofosbuvir/Ledipasvir without ribavirin achieved high sustained virologic response for hepatitis $\mathrm{C}$ recurrence after liver transplantation: two-center experience. Transplantation. 2017;101(5):996-1000. https://doi.org/10.1097/TP. 0000000000001467.

37. Madan S, Patel SR, Rahgozar K, Saeed O, Murthy S, Vukelic $S$, et al. Utilization rates and clinical outcomes of hepatitis $\mathrm{C}$ positive donor hearts in the contemporary era. J Heart Lung Transplant. 2019;38(9):907-17. https://doi.org/10.1016/j.healun.2019.06.023

This analysis of the UNOS registry between 2015 and 2018 assessed the utilization of HCV positive donor hearts and the incidnece of primary graft dysfunction and 1 year survival of recipients.

38. Morris KL, Adlam JP, Padanilam M, Patel A, GarciaCortes R, Chaudhry SP, et al. Hepatitis C donor viremic cardiac transplantation: a practical approach. Clin Transpl. 2020;34(1):e13764. https://doi.org/10.1111/ ctr.13764.

39.• Schlendorf KH, Zalawadiya S, Shah AS, Perri R, Wigger M, Brinkley DM, et al. Expanding heart transplant in the era of direct-acting antiviral therapy for hepatitis $\mathrm{C}$. JAMA Cardiol. 2020;5(2):167-74. https://doi.org/10. 1001/jamacardio.2019.4748

This prospective single center study observational study reports transplant recipient outcomes from HCV positive donors and demonstrated equivalent 1-year survival when compared to HCV negative donors.

40. Lin S-N, Tsai M-K, Luo C-Y, Lee C-Y, Hu R-H, Lee J-M et al. Outcomes of solid organ transplantation from an HIV positive donor to negative recipients. Am J Transplant. 2016;16:suppl 3.

41. Muller E, Barday Z, Kahn D. HIV-positive-to-HIVpositive kidney transplantation. N Engl J Med.
2015;372(21):2070-1. https://doi.org/10.1056/ NEJMc1503288.

42. DeFilippis EM, Farr MA, Givertz MM. Challenges in heart transplantation in the era of COVID-19. Circulation. 2020;141(25):2048-51. https://doi.org/10. 1161/CIRCULATIONAHA.120.047096.

43. Copeland H, Hayanga JWA, Neyrinck A, MacDonald P, Dellgren G, Bertolotti A, et al. Donor heart and lung procurement: a consensus statement. J Heart Lung Transplant. 2020;39(6):501-17. https://doi.org/10. 1016/j.healun.2020.03.020.

44. D'Amico TA, Meyers CH, Koutlas TC, Peterseim DS, Sabiston DC Jr, Van Trigt P, et al. Desensitization of myocardial beta-adrenergic receptors and deterioration of left ventricular function after brain death. J Thorac Cardiovasc Surg. 1995;110(3):746-51. https://doi.org/ 10.1016/s0022-5223(95)70107-9.

45. Bosso FJ, Allman FD, Pilati CF. Myocardial work load is a major determinant of norepinephrine-induced left ventricular dysfunction. Am J Phys. 1994;266(2 Pt 2):H531-9. https://doi.org/10.1152/ajpheart.1994. 266.2.H531.

46. Pennefather SH, Bullock RE, Mantle D, Dark JH. Use of low dose arginine vasopressin to support brain-dead organ donors. Transplantation. 1995;59(1):58-62. https://doi.org/10.1097/00007890-19950115000011.

47. Stoica SC, Satchithananda DK, White PA, Parameshwar J, Redington AN, Large SR. Noradrenaline use in the human donor and relationship with load-independent right ventricular contractility. Transplantation. 2004;78(8):1193-7. https://doi.org/10.1097/01.tp. $0000137792.74940 .4 f$.

48. Kutschmann M, Fischer-Frohlich CL, Schmidtmann I, Bungard S, Zeissig SR, Polster F, et al. The joint impact of donor and recipient parameters on the outcome of heart transplantation in Germany after graft allocation. Transpl Int. 2014;27(2):152-61. https://doi.org/10. 1111/tri.12221.

49. Rosendale JD, Kauffman HM, McBride MA, Chabalewski FL, Zaroff JG, Garrity ER, et al. Hormonal resuscitation yields more transplanted hearts, with improved early function. Transplantation. 2003;75(8):1336-41. https://doi.org/10.1097/01.TP. 0000062839.58826.6D.

50. Chen JM, Cullinane S, Spanier TB, Artrip JH, John R, Edwards NM, et al. Vasopressin deficiency and pressor hypersensitivity in hemodynamically unstable organ donors. Circulation. 1999;100(19 Suppl):II244-6. https://doi.org/10.1161/01.cir.100.suppl_2.ii-244.

51. Venkateswaran RV, Steeds RP, Quinn DW, Nightingale $\mathrm{P}$, Wilson IC, Mascaro JG, et al. The haemodynamic effects of adjunctive hormone therapy in potential heart donors: a prospective randomized double-blind factorially designed controlled trial. Eur Heart J. 2009;30(14):1771-80. https://doi.org/10.1093/ eurheartj/ehp086.

52. Macdonald PS, Aneman A, Bhonagiri D, Jones D, O'Callaghan G, Silvester W, et al. A systematic review 
and meta-analysis of clinical trials of thyroid hormone administration to brain dead potential organ donors. Crit Care Med. 2012;40(5):1635-44. https://doi.org/ 10.1097/CCM.0b013e3182416ee7.

53. Hicks M, Hing A, Gao L, Ryan J, Macdonald PS. Organ preservation. Methods Mol Biol. 2006;333:331-74. https://doi.org/10.1385/1-59745-049-9:331.

54. Naito N, Funamoto M, Pierson RN, D'Alessandro DA. First clinical use of a novel hypothermic storage system for a long-distance donor heart procurement. J Thorac Cardiovasc Surg. 2020;159(2):e121-e3. https://doi. org/10.1016/j.jtcvs.2019.05.085.

55. Chien SF, Diana JN, Oeltgen PR, Salley R. Functional studies of the heart during a 24-hour preservation using a new autoperfusion preparation. J Heart Lung Transplant. 1991;10(3):401-8.

56. Hardesty RL, Griffith BP. Autoperfusion of the heart and lungs for preservation during distant procurement. J Thorac Cardiovasc Surg. 1987;93(1):11-8.

57. Ardehali A, Esmailian F, Deng M, Soltesz E, Hsich E, Naka Y, et al. Ex-vivo perfusion of donor hearts for human heart transplantation (PROCEED II): a prospective, open-label, multicentre, randomised noninferiority trial. Lancet. 2015;385(9987):2577-84. https://doi.org/10.1016/S0140-6736(15)60261-6.

58.• Chan JL, Kobashigawa JA, Reich HJ, Ramzy D, Thottam $\mathrm{MM}, \mathrm{Yu} \mathrm{Z}$, et al. Intermediate outcomes with ex-vivo allograft perfusion for heart transplantation. J Heart Lung Transplant. 2017;36(3):258-63. https://doi.org/ 10.1016/j.healun.2016.08.015

This single center prospective trial studied the 2-year posttransplant outcomes of donor hearts randomized to standard cold storage or Organ Care System.

59. Schroder JN, D'Alessandro D, Esmailian F, Boeve T, Tang P, Liao K, et al. Successful utilization of extended criteria donor (ECD) hearts for transplantation - results of the OCS $^{\mathrm{TM}}$ heart EXPAND trial to evaluate the effectiveness and safety of the OCS heart system to preserve and assess ECD hearts for transplantation. J Heart Lung Transplant. 2019;38(4):S42.

60. Nilsson J, Jernryd V, Qin G, Paskevicius A, Metzsch C, Sjoberg T, et al. A nonrandomized open-label phase 2 trial of nonischemic heart preservation for human heart transplantation. Nat Commun. 2020;11(1):2976. https://doi.org/10.1038/s41467020-16782-9.

61. Barnard CN. The operation. A human cardiac transplant: an interim report of a successful operation performed at Groote Schuur Hospital, Cape Town. S Afr Med J. 1967;41(48):1271-4.

62.• Messer S, Page A, Axell R, Berman M, HernandezSanchez J, Colah S, et al. Outcome after heart transplantation from donation after circulatory-determined death donors. J Heart Lung Transplant. 2017;36(12):1311-8. https://doi.org/10.1016/j. healun.2017.10.021

This observational study reports the transplant outcome of DCD hearts retrieved with NRP-ESP and DP-ESP. They found comparable outcomes to recipients from DBD donors.

63.• Chew HC, Iyer A, Connellan M, Scheuer S, Villanueva J, Gao L, et al. Outcomes of donation after circulatory death heart transplantation in Australia. J Am Coll Cardiol. 2019;73(12):1447-59. https://doi.org/10. 1016/j.jacc.2018.12.067

This study describes the St. Vincent's Hospital group's experience of DCD heart transplant and their transplant outcome.

64. Rudd DM, Dobson GP. Eight hours of cold static storage with adenosine and lidocaine (Adenocaine) heart preservation solutions: toward therapeutic suspended animation. J Thorac Cardiovasc Surg. 2011;142(6):1552-61. https://doi.org/10.1016/j.jtcvs. 2011.05.023.

65. White CW, Ambrose E, Muller A, Li Y, Le H, Thliveris J, et al. Avoidance of profound hypothermia during initial reperfusion improves the functional recovery of hearts donated after circulatory death. Am J Transplant. 2016;16(3):773-82. https://doi.org/10.1111/ajt. 13574.

66. Iyer A, Gao L, Doyle A, Rao P, Cropper JR, Soto C, et al. Normothermic ex vivo perfusion provides superior organ preservation and enables viability assessment of hearts from DCD donors. Am J Transplant. 2015;15(2):371-80. https://doi.org/10.1111/ajt. 12994.

67. Messer S, Page A, Berman M, Colah S, Dunning J, Pavlushkov E, et al. First to 50: early outcomes following heart transplantation at Royal Papworth Hospital from donation after circulatory determined death (DCD) donors. J Heart Lung Transplant. 2019;38(4):S43.

68. Dhital K, Ludhani P, Scheuer S, Connellan M, Macdonald P. DCD donations and outcomes of heart transplantation: the Australian experience. Indian J Thorac Cardiovasc Surg. 2020;36(Suppl 2):224-32. https://doi.org/10.1007/s12055-020-00998-x.

\section{Publisher's Note}

Springer Nature remains neutral with regard to jurisdictional claims in published maps and institutional affiliations. 